\title{
Serotonergic Polymorphisms and Psychotic Disorders in Populations From North Spain
}

\author{
I. Mata, ${ }^{1}$ M.J. Arranz, ${ }^{2 *}$ A. Patiño, ${ }^{3}$ T. Lai, ${ }^{2}$ M. Beperet, ${ }^{1}$ L. Sierrasesumaga, ${ }^{3}$ D. \\ Clark, ${ }^{2}$ F. Perez-Nievas, ${ }^{1}$ L. Richards, ${ }^{2}$ F. Ortuño, ${ }^{3}$ P. Sham, ${ }^{2}$ and R.W. Kerwin ${ }^{2}$ \\ ${ }^{1}$ Fundacion Argibide, Pamplona (Navarra), Spain \\ ${ }^{2}$ Division of Psychological Medicine, Institute of Psychiatry, KCL, London, United \\ Kingdom \\ ${ }^{3}$ Departamentos de Pediatria y Psiquiatria, Universidad de Navarra, Spain
}

*Correspondence to: Dr. M.J. Arranz

Clinical Neuropharmacology, Psychological Medicine, Institute

of Psychiatry, KCL, Denmark Hill, London SE5 8AF.

E-mail: m.arranz@iop.kcl.ac.uk

\begin{abstract}
There is strong biological evidence relating alterations in the serotonergic system with mental disorders. These alterations may be originated at the DNA level by sequence mutations that alter the functioning of serotonin receptors and transporter. To test this hypothesis we investigated three genetic variants of the 5-HT2A receptor (-1438G/A, $102 \mathrm{~T} / \mathrm{C}$ and His452Tyr) and two variants of the serotonin transporter (a VNTR in the second intron and a $44 \mathrm{bp}$ insertion/delition in the promoter region of the gene) in a clinical sample recruited in a human isolate and in surrounding areas in Northern Spain $(\mathrm{N}=257)$ and in ethnically matched controls $(\mathrm{N}=334)$. No clear association was found between 5-HT2A variants and psychosis. However, marginal associations were observed between the 5-HTT LPR and VNTR variants and psychosis $(\mathrm{P} \leq 0.05)$ indicating a minor contribution to psychosis of genetic alterations in this gene.
\end{abstract}

\section{KEY WORDS}

serotonin; schizophrenia; psychoses; 5-HT2A; 5-HTT 


\section{INTRODUCTION}

The serotonergic system has been suggested to regulate sleep, appetite, pain, and sexual behaviour and to contribute to anxiety, mood disorders, suicidal behaviour and additional symptomatology related to psychotic disorders. This hypothetical involvement of the serotonergic system in the aetiology of mental disorders has been supported by alterations in the expression of serotonin (5-HT) receptors and transporter observed in the brain of patients with schizophrenia [Burnet et al., 1996; Hernandez and Sokolov, 1997; Dean et al., 1999; Pralong et al., 2000]. Epidemiological studies have proved the genetic contribution to the development of mental disorders [McGuffin et al., 2002] and mutations in serotonin proteins may be responsible for system alterations. However, association and linkage genetic studies have failed to produce consistent results supporting the involvement of serotonergic mutations in mental illnesses such as schizophrenia and bipolar disorder. Polymorphisms in the gene coding for 5-HT2A receptors have been related to schizophrenia, bipolar disorder and psychotic symptomatology [Inayama et al., 1996; Williams et al., 1996; Du et al., 1999; Joober et al., 1999; Nacmias et al., 2001; Araga and Narasu, 2002; Bonnier et al., 2002; Golimbet et al., 2002]. Genetic variants of the serotonin transporter (5-HTT) have also been associated with psychotic disorders [Collier et al., 1996; Malhotra et al., 1998; Hranilovic et al., 2000; Kaiser et al., 2001; Tsai et al., 2002]. However, there is also a wealth of publications that fail to support these findings [Gutierrez et al., 1995; Arranz et al., 1996; Rao et al., 1998; Shinkai et al., 1998; He et al., 1999; Oliveira et al., 2000; Haider and Zahid, 2002; Serretti et al., 2002]. Discordant findings in studies of complex genetic diseases have been attributed to disease heterogeneity although other factors such as sample size, ethnic origin and symptomatology may also influence results. We have tried to clarify these results by investigating serotonergic polymorphisms in a relatively large cohort of psychotic patients $(\mathrm{N}=257)$ and controls $(\mathrm{N}=334)$. A subgroup of this cohort $(\mathrm{N}=162$ patients and 180 controls $)$ was recruited from a population isolate from North Navarre (Spain) where the Basque population originated. It has been suggested that the lower level of heterogeneity present in isolate populations may help the identification of genetic factors contributing to complex diseases. Three polymorphisms in the 5-HT2A receptor gene $(102 \mathrm{~T} / \mathrm{C},-1438 \mathrm{G} / \mathrm{A}$ and His452Tyr) and two polymorphisms previously described in the 5-HTT gene (designated as LPR and VNTR) were investigated in the samples and compared with ethnically matched controls to investigate their contribution to mental disorders. The results showed marginal associations $(\mathrm{P}<0.05)$ between the 5-HTT LPR and VNTR polymorphisms and schizophrenia, although no significant differences were observed in the distribution of 5-HT2A variants between patients and controls. Our results do not support a major role of the serotonergic system on the aetiology of schizophrenia, although a minor contribution of the serotonin transporter is likely.

\section{MATERIALS AND METHODS}

\section{Clinical Sample}

Patient sample. Two hundred and fifty seven subjects (153 males and 104 females) suffering from psychotic disorders (DSM-IV diagnosis) were recruited for the study. One hundred and eighty two of the patients had a diagnosis of schizophrenia and 18 of 
schizo-affective disorder, 28 subjects suffered from bipolar disorder, 15 subjects suffered from major depression, 7 subjects presented delusional disorder and 7 brief psychotic disorders. Patients were recruited in several medical centres in Pamplona (Navarre, Spain) and were of Spanish origin $(\mathrm{N}=95: 77$ schizophrenia, 9 schizoaffective disorder, 3 bipolar disorder, 1 major depression, 5 brief psychotic disorder) or were recruited from an isolate area in the Northern part of Navarre and were of Basque origin ( $\mathrm{N}=162$ : 105 schizophrenia, 9 schizo-affective disorder, 25 bipolar disorder, 14 major depression, 7 delusional disorder, 2 brief psychotic disorder). The Basques constitute one of the oldest human isolates and present several unique characteristics that differentiate them from other Spanish and European populations [Bertranpetit and Cavalli-Sforza, 1991]. In addition, the small population size and the geographical isolation of the area in North Navarre where this sample was collected guarantee low genetic heterogeneity and high level of linkage disequilibrium, two characteristics that should help to identify genes implicated in complex disorders. The ethnic origin of all subjects was confirmed at grandparent level. The average age of the patient subjects was $40.66(\mathrm{SD}=14.43)$ and the mean for age of onset was $23.78(\mathrm{SD}=8.08)$.

Control sample. Ethnically matched samples consisting of 154 controls of Spanish origin and 180 of Basque origin (collected in the same isolate area than the patients) were recruited in blood bank centres. The average age of the control sample was 26.89 $(\mathrm{S} . \mathrm{D}=5.45)$ and the gender distribution was 177 males and 157 females. This relatively large cohort has a statistical power of more than $85 \%$ to detect genetic effects with an odds ratio superior to 2.00 for polymorphisms with a frequency of $10 \%$. Informed consent was obtained from all participants in the study. Ethical approval was granted by the respective committes of all collaborating institutions.

\section{Genotype Characterisation}

Three 5-HT2A polymorphisms (102T/C, - 1438G/A, His452Tyr) and two 5-HTT polymorphisms (a VNTR in the second intron, and a polymorphic insertion/deletion of a $44 \mathrm{bp}$ fragment located in the promoter region of the gene, designated as 5-HTT LPR) were investigated in the samples. Duplicate independent assays were performed for each individual and polymorphism. The PCR methods used were similar to those described elsewhere [Arranz et al., 1995; Arranz et al., 1996; Collier et al., 1996]. Fluorescent labels (FAM and HEX) were added to the 5' end of primers to facilitate the genotyping process using an ABI 3100 automated genotyper (samples prepared for automatic genotyping following manufacturer's instructions).

\section{Statistical Analyses}

As the clinical samples consisted of two population groups of different ethnic origin, stratified analyses were performed for all comparisons. Chi-square comparisons were performed using SPSS (version 10.0) and EPIInfo2000 statistical packages. Haplotype analyses were performed using the EHPlus programme [Zhao et al., 2000]. 


\section{RESULTS}

\section{5-HT2A 102T/C}

A total of 244 patients and 309 controls were analysed for this polymorphism (see Table I). A similar trend to that observed in previous studies was observed in the genotype distribution between patients and controls: individuals homozygous for the 102-C variant were relatively more frequent in psychotic patients than in controls (29 and 27\% for Basque patients and controls, 25 and $24 \%$ for Spanish patients and controls respectively). This trend was slightly increased when only schizophrenic and schizoaffective patients were considered: an average of $30 \%$ patients presented the $102-\mathrm{C} / \mathrm{C}$ genotype in comparison to $25 \%$ on average in controls presented. However, these differences did not reach statistical significance $\left(\chi^{2}=1.73, \mathrm{P}=0.42\right.$ and $\chi^{2}=0.24, \mathrm{P}=$ 0.89 for Basque and Spanish samples respectively; $\chi^{2}=1.73, \mathrm{P}=0.42$ for stratified analyses). No differences in allelic distribution were observed between patients and controls (frequency of 102-T $=0.45-0.48$, frequency of $102-\mathrm{C}=0.52-0.56$ in both diagnostic and ethnic groups).

\section{5-HT2A -1438G/A}

Table II summarises the results for this polymorphism. A total of 239 patients and 305 control subjects were investigated. Nearly complete linkage disequilibrium was observed between the $-1438 \mathrm{G} / \mathrm{A}$ and $102 \mathrm{~T} / \mathrm{C}$ polymorphisms in both Spanish and Basque subjects. As expected, the results were similar to those of $102 \mathrm{~T} / \mathrm{C}$, the only differences being the result of failed PCR assays in several samples. Individuals with the $-1438 \mathrm{G} / \mathrm{G}$ genotype were slightly more frequent in patients (28-31\%) than controls (27\% on average) without reaching statistical significance (stratified analyses of genotypes vs. disease: $\chi^{2}=1.36, \mathrm{P}=0.51 ; \chi^{2}=3.23, \mathrm{P}=0.20$ when only schizophrenic and schizo-affective patients were considered). Allele frequencies were again similar in patients and controls (frequency of -1438G: 0.55-56, frequency of -1438A: 0.44-46, on average).

\section{5-HT2A His452Tyr}

This polymorphism was found in $18 \%$ of patients and $15 \%$ of controls (Table III). Allele and genotype distributions were similar in Basques and Spanish, and among patients and controls. Slightly higher frequencies of individuals heterozygous were found in patients (16\% in Basques and $21 \%$ in Spanish) than in controls (14 and 16\% for Basque and Spanish controls respectively). The frequency of the rare allele, Tyr452, ranged from 0.09 to 0.11 in patients to $0.07-0.08$ in controls. These differences did not reach statistical significance $(\mathrm{P}>0.30$ for all comparisons).

\section{5-HTT LPR}

Individuals homozygous for the $480 \mathrm{bp}$ allele were more frequently detected among controls (36\% of Basque controls and $29 \%$ of Spanish controls presented the 480/480 bp genotype, vs. 31 and $20 \%$ of Basque and Spanish patients respectively, Table IV). 
Stratified analysis of these results showed a marginal association between genotype distribution and psychosis $\left(\chi^{2}=6.04, \mathrm{P}=0.05\right.$, stratified analyses $)$. A similar observation was obtained when comparing the subgroup of schizophrenic and schizoaffective patients $\left(24 \%\right.$ of 480 bp homozygotes) versus controls $(33 \%)\left(\chi^{2}=6.20\right.$, $\mathrm{P}=0.045)$. Comparisons of allelic distribution produced no significant values $(\mathrm{P}>0.20$ for all comparisons). The frequency of allele $480 \mathrm{bp}$ ranged from 0.50 to 0.57 in patients and controls.

\section{5-HTT VNTR}

Three allelic variants of this polymorphism $(9,10$ and 12 repeats) were detected in the samples (Table V). Schizophrenic patients presented a higher proportion of 12 repeat homozygotes (45\% of Basque patients and $47 \%$ of Spanish patients) than controls (41 and $36 \%$ of Basque and Spanish controls respectively; $\left.\chi^{2}=5.15, \mathrm{P}=0.16\right)$. Chi-square comparisons of allelic distribution revealed a significant difference of the 12 repeat allele frequency in patients versus controls (0.69 and 0.65 in Basque patients and controls, and 0.68 and 0.58 in Spanish patients and controls respectively; $\chi^{2}=3.89, \mathrm{P}=$ 0.05). Similar genotype and allele distributions were observed in the schizophrenia/schizo-affective subgroup, although comparisons versus frequencies in controls did not reveal statistically significant differences probably due to the reduction in sample since $\mathrm{P}>0.05$ for all comparisons.

\section{Haplotype Analyses}

Haplotype analyses showed strong linkage disequilibrium between the three 5-HT2A polymorphisms investigated, independent of disease $\left(\chi^{2}=888\right.$, df $\left.=7, \mathrm{P}<0.0001\right)$. However, no haplotype combination was found to be associated with disease phenotype $\left(\chi^{2}=8.82\right.$, df $\left.=7, \mathrm{P}=0.27\right)$. Similar results were obtained for 5-HTT haplotype comparisons between patients and controls: the 5-HTT VNTR and LTR polymorphisms were found in strong linkage disequilibrium $\left(\chi^{2}=62.87\right.$, df $\left.=3, \mathrm{P}<0.0001\right)$ but no differences in haplotype combinations were observed between patients and controls $\left(\chi^{2}=6.04, \mathrm{df}=3, \mathrm{P}=0.11\right)$.

\section{DISCUSSION}

The serotonergic hypothesis of schizophrenia suggests that alterations in this neurotransmitter system may be related to the aetiology of the disease [Meltzer, 1999]. Genetic polymorphisms may contribute to these alterations and this possibility has been the subject of extensive study. Previous association studies on 5 HT2A and 5-HTT polymorphisms showed contradicting results that may have been affected by sample size and genetic heterogeneity. We tried to clarify these results by genotyping five serotonergic polymorphisms in a relatively large sample of psychotic patients and controls from Northern Spain, including individuals from a human isolate of Basque origin in Navarre.

Three polymorphisms in the gene coding for the 5-HT2A receptor $(102 \mathrm{~T} / \mathrm{C},-1438 \mathrm{G} / \mathrm{A}$ and His452Tyr) and two genetic variants in the serotonin transporter (5-HTT) gene were 
genotyped in the samples. Although the Basques constitute one of the oldest human isolates with unique characteristics [Bertranpetit and Cavalli-Sforza, 1991] no significant differences were observed in the genotype or allelic distribution between Spanish and Basque individuals for any of the polymorphisms investigated. Furthermore, when differences in genotype or allele frequency distribution were observed between psychotic patients and controls, a similar trend was observed in the Spanish and Basque samples, indicating a similar contribution to psychotic disorders (or lack of involvement) in both populations.

Our results failed to show any significant difference in the genotype or allele distribution of 5-HT2A variants in any of the subgroups and comparisons considered. In addition, there was no clear trend of differential distribution between patients and controls. These results could not confirm previous findings of association with schizophrenia [Inayama et al., 1996; Williams et al., 1996; Joober et al., 1999; Araga and Narasu, 2002]. However, it is likely that serotonergic associations are stronger when specific phenotypes such as suicidal behaviour and clinical dimensions are considered [Bonnier et al., 2002; Golimbet et al., 2002] and therefore could not be detected in our sample. Alleles $102 \mathrm{~T}$ and $-1438 \mathrm{~A}$, and alleles $102 \mathrm{C}$ and $-1438 \mathrm{G}$ were in nearly complete linkage disequilibrium in both populations. Similar linkage status has been observed in other European populations [Arranz et al., 1998].

Marginal associations of 5-HTT polymorphic variants with schizophrenia were detected in our sample. Association was observed between the 5-HTT LPR polymorphism and schizophrenia, with a slightly higher frequency of the allele $528 \mathrm{bp}$ observed in patients. These frequencies differ slightly from those observed in other Spanish populations [Gutierrez et al., 1998] and may be caused by heterogeneity or chance finding. A marginal association was also observed with the 5-HTT VNTR polymorphism: an excess of the 12 repeat allele was observed in patients in comparison with controls $(\mathrm{P}=$ 0.05). This finding had also been found in Chinese and European schizophrenic patients [Hranilovic et al., 2000; Tsai et al., 2002], patients suffering schizoparanoid disorders [Kaiser et al., 2001] and bipolar patients [Collier et al., 1996]. Although our results would not be statistically significant if Bonferoni corrections were applied, the coincidence with previous findings strengthens the hypothesis of a minor contribution of 5-HTT polymorphisms in the aetiology of psychotic disorders.

In summary, our results do not support a major involvement of 5-HT2A genetic variants in the aetiology of schizophrenia. However, the marginal associations observed with 5HTT variants indicate a minor contribution to the disease. It is likely that stronger associations can be found when specific clinical dimensions are investigated, especially if a low heterogeneity sample is used.

\section{REFERENCES}

$\Rightarrow$ Araga US, Narasu ML. 2002. Association between the 102T/C polymorphism of serotonin-2A receptor gene and schizophrenia among South Indians. Mol Psychiatry 7(6):540-541.

$\Rightarrow$ Arranz MJ, Collier DA, Sodhi M, Ball D, Roberts G, Price J, et al. 1995. Association between clozapine response and allelic variation in the 5-HT2A receptor gene. Lancet 346:281-282. 
$\Rightarrow$ Arranz MJ, Lin MW, Powell J, Kerwin R, Collier D. 1996. 5HT 2a receptor T102C polymorphism and schizophrenia. Lancet 347(9018):1831-1832.

$\Rightarrow$ Arranz MJ, Collier DA, Munro J, Sham P, Kirov G, Sodhi M, et al. 1996. Analysis of a structural polymorphism in the 5-HT2A receptor and clinical response to clozapine. Neurosci Lett 217:177-178.

$\Rightarrow$ Arranz MJ, Munro J, Owen MJ, Spurlock J, Sham P, Zhao J, et al. 1998. Evidence for association between polymorphisms in the promoter and coding regions of the 5-HT2A receptor gene and response to clozapine. Mol Psychiatry 3:61-66.

$\Rightarrow$ Bertranpetit J, Cavalli-Sforza LL. 1991. A genetic reconstruction of the history of the population of the Iberian Peninsula. Ann Hum Genet 55(Pt 1):51-67.

$\Rightarrow$ Bonnier B, Gorwood P, Hamon M, Sarfati Y, Boni C, Hardy-Bayle MC. 2002. Association of 5-HT(2A) receptor gene polymorphism with major affective disorders: The case of a subgroup of bipolar disorder with low suicide risk. Biol Psychiatry 51(9):762-765.

$\Rightarrow$ Burnet PW, Eastwood SL, Harrison PJ. 1996. 5-HT1A and 5-HT2A receptor mRNAs and binding site densities are differentially altered in schizophrenia. Neuropsychopharmacology 15(5):442-455.

$\Rightarrow$ Collier DA, Stober G, Li T, Heils A, Catalano M, Di Bella D, et al. 1996. A novel functional polymorphism within the promoter of the serotonin transporter gene: Possible role in susceptibility to affective disorders. Mol Psychiatry 1(6):453-460.

$\Rightarrow$ Collier DA, Arranz MJ, Sham P, Battersby S, Vallada H, Gill P, et al. 1996. The serotonin transporter is a potential susceptibility factor for bipolar affective disorder. Neuroreport 7(10):1675-1679.

$\Rightarrow$ Dean B, Hussain T, Hayes W, Scarr E, Kitsoulis S, Hill C, et al. 1999. Changes in serotonin2A and GABA(A) receptors in schizophrenia: Studies on the human dorsolateral prefrontal cortex. J Neurochem 72(4):1593-1599.

$\Rightarrow$ Du L, Faludi G, Palkovits M, Demeter E, Bakish D, Lapierre YD, et al. 1999. Frequency of long allele in serotonin transporter gene is increased in depressed suicide victims. Biol Psychiatry 46(2):196-201.

$\Rightarrow$ Golimbet VE, Alfimova MV, Manandyan KK, Mitushina NG, Abramova LI, Kaleda VG, et al. 2002. 5HTR2A gene polymorphism and personality traits in patients with major psychoses. Eur Psychiatry 17(1):24-28.

$\Rightarrow$ Gutierrez B, Arranz M, Fananas L, Valles V, Guillamat R, Van Os J, et al. 1995. 5HT2A receptor gene and bipolar affective disorder. Lancet 346(8980):969.

$\Rightarrow$ Gutierrez B, Arranz MJ, Collier DA, Valles V, Guillamat R, Bertranpetit J, et al. 1998. Serotonin transporter gene and risk for bipolar affective disorder: An association study in Spanish population. Biol Psychiatry 43(11):843-847.

$\Rightarrow$ Haider MZ, Zahid MA. 2002. No evidence for an association between the 5hydroxytryptamine 5-HT2a receptor gene and schizophrenia in Kuwaiti Arabs. Psychiatry Clin Neurosci 56(4):465-467.

$\Rightarrow \mathrm{He}$ L, Li T, Melville C, Liu S, Feng GY, Gu NF, et al. 1999. 102T/C polymorphism of serotonin receptor type $2 \mathrm{~A}$ gene is not associated with schizophrenia in either Chinese or British populations. Am J Med Genet 88(1):95-98.

$\Rightarrow$ Hernandez I, Sokolov BP. 1997. Abnormal expression of serotonin transporter mRNA in the frontal and temporal cortex of schizophrenics. Mol Psychiatry 2(1):57-64. 
$\Rightarrow$ Hranilovic D, Schwab SG, Jernej B, Knapp M, Lerer B, Albus M, et al. 2000. Serotonin transporter gene and schizophrenia: Evidence for association/ linkage disequilibrium in families with affected siblings. Mol Psychiatry 5(1):91-95.

$\Rightarrow$ Inayama Y, Yoneda H, Sakai T, Ishida T, Nonomura Y, Kono Y, et al. 1996. Positive association between a DNA sequence variant in the serotonin $2 \mathrm{~A}$ receptor gene and schizophrenia. Am J Med Genet 67(1):103-105.

$\Rightarrow$ Joober R, Benkelfat C, Brisebois K, Toulouse A, Turecki G, Lal S, et al. 1999. T102C polymorphism in the 5HT2Agene and schizophrenia: Relation to phenotype and drug response variability. J Psychiatry and Neurosci 24:141-146.

$\Rightarrow$ Kaiser R, Tremblay PB, Schmider J, Henneken M, Dettling M, MullerOerlinghausen B, et al. 2001. Serotonin transporter polymorphisms: No association with response to antipsychotic treatment, but associations with the schizoparanoid and residual subtypes of schizophrenia. Mol Psychiatry 6(2):179-185.

$\Rightarrow$ Malhotra AK, Goldman D, Mazzanti C, Clifton A, Breier A, Pickar D. 1998. A functional serotonin transporter (5-HTT) polymorphism is associated with psychosis in neuroleptic-free schizophrenics. Mol Psychiatry 3(4):328-332.

$\Rightarrow$ McGuffin P, Owen MJ, Gottesman II. 2002. Psychiatric Genetics and Genomics. 1st edn. Oxford: Oxford University Press.

$\Rightarrow$ Meltzer HY. 1999. The role of serotonin in antipsychotic drug action. Neuropsychopharmacology 21(2):s106-s115.

$\Rightarrow$ Nacmias B, Tedde A, Forleo P, Piacentini S, Guarnieri BM, Bartoli A, et al. 2001. Association between 5-HT(2A) receptor polymorphism and psychotic symptoms in Alzheimer's disease. Biol Psychiatry 50(6):472-475.

$\Rightarrow$ Oliveira JR, Carvalho DR, Pontual D, Gallindo RM, Sougey EB, Gentil V, et al. 2000. Analysis of the serotonin transporter polymorphism (5-HTTLPR) in Brazilian patients affected by dysthymia, major depression and bipolar disorder. Mol Psychiatry 5(4):348-349.

$\Rightarrow$ Pralong D, Tomaskovic-Crook E, Opeskin K, Copolov D, Dean B. 2000. Serotonin(2A) receptors are reduced in the planum temporale from subjects with schizophrenia. Schizophr Res 44(1):35-45.

$\Rightarrow$ Rao D, Jonsson EG, Paus S, Ganguli R, Nothen M, Nimgaonkar VL. 1998. Schizophrenia and the serotonin transporter gene. Psychiatr Genet 8(4):207-212.

$\Rightarrow$ Serretti A, Lilli R, Lorenzi C, Lattuada E, Cusin C, Smeraldi E. 2002. Serotonin transporter gene (5-HTTLPR) and major psychoses. Mol Psychiatry 7(1):95-99.

$\Rightarrow$ Shinkai T, Ohmori O, Kojima H, Terao T, Suzuki T, Abe K. 1998. Negative association between T102C polymorphism of the 5-HT2a receptor gene and schizophrenia in Japan. Hum Hered 48(4):212-215.

$\Rightarrow$ Tsai SJ, Ouyang WC, Hong CJ. 2002. Association for serotonin transporter gene variable number tandem repeat polymorphism and schizophrenic disorders. Neuropsychobiology 45(3):131-133.

$\Rightarrow$ Williams J, Spurlock J, McGuffin P, Mallet J, Noethen MM, Gill M, et al. 1996. Association between schizophrenia and T102C polymorphism of the 5hydroxytryptamine type 2a-receptor gene. Lancet 347:1294-1296.

$\Rightarrow$ Zhao JH, Curtis D, Sham PC. 2000. Model-free analysis and permutation tests for allelic associations. Hum Hered 50(2):133-139. 


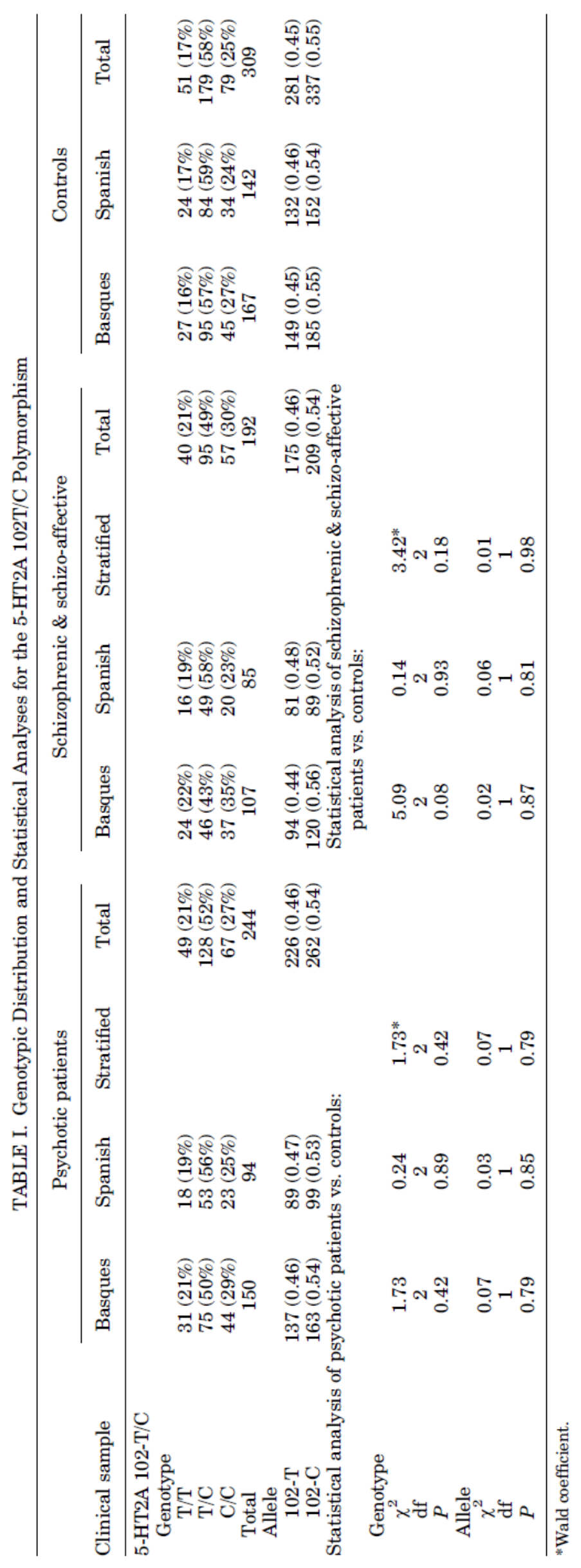




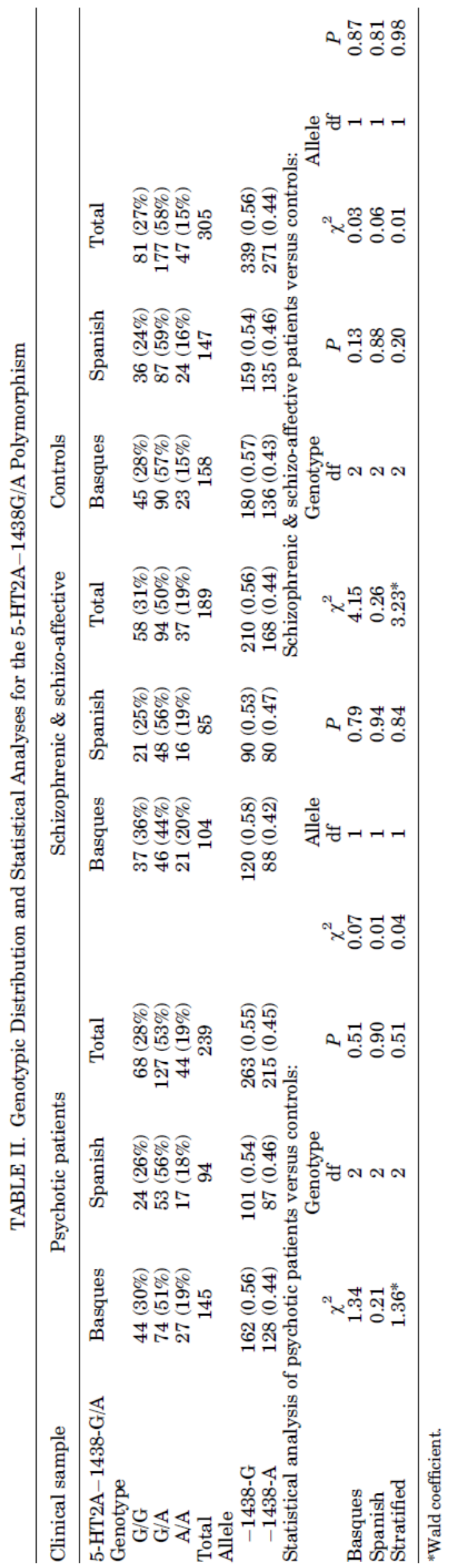




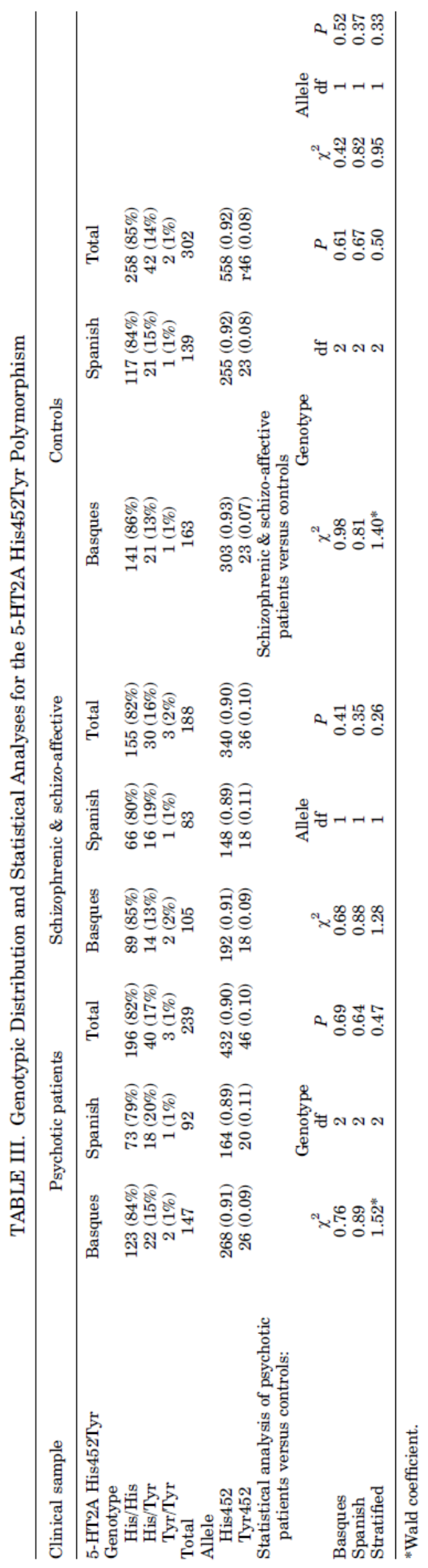




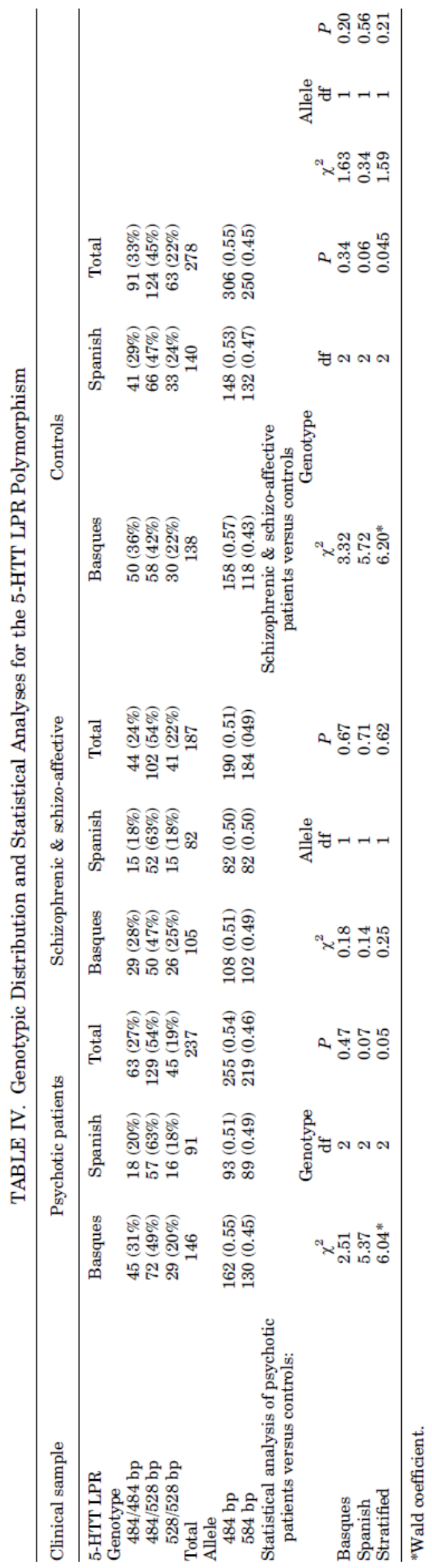




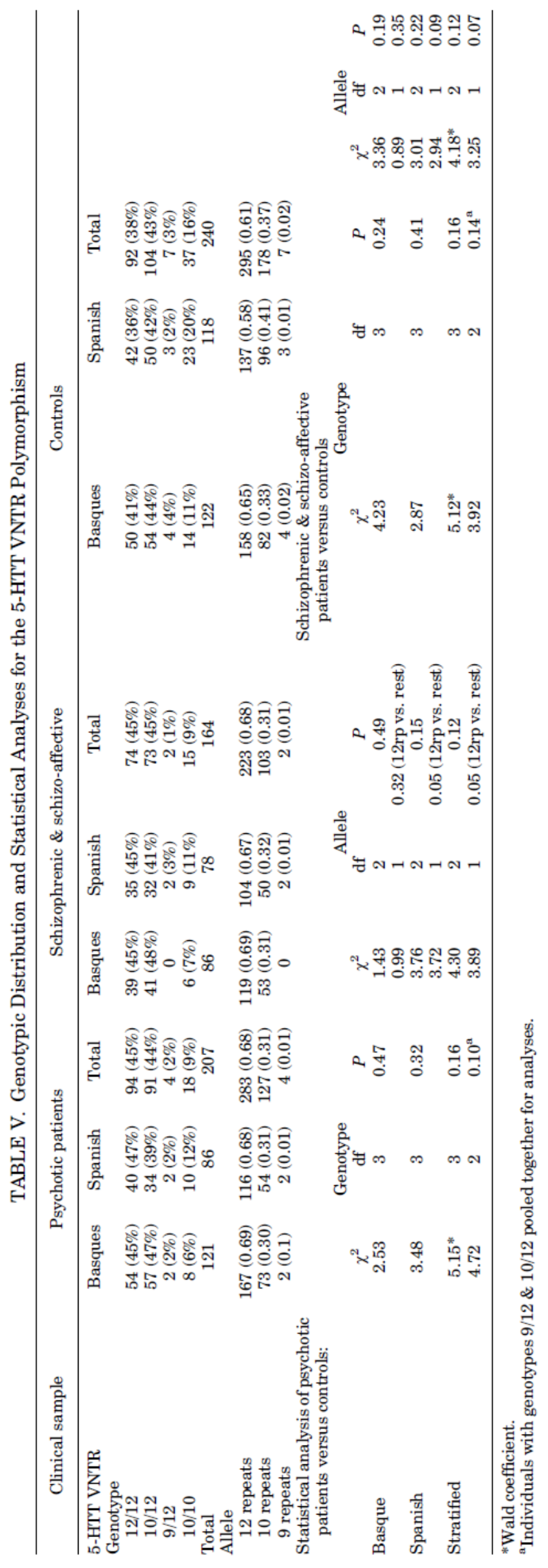

